\title{
WPW Syndrome: Review of the Evidence
} \author{
and Hossein Esmaeili* ${ }^{1 *}$ \\ ${ }^{1}$ Young Researcher and Elite Clube, Tehran Medical Sciences, Islamic Azad University, Iran \\ ${ }^{2}$ Medical Student, Department of Medicine, Islamic Azad University Tehran Medical Sciences, Iran \\ ${ }^{3}$ Bachelor of Science in Nursing, Islamic Azad University Semnan Branch, Iran
}

Maryam Mahdavi Afshar ${ }^{1}$, Mohammad Hossein Moshaver ${ }^{1}$, Zahra Khodamoradi ${ }^{2}$, Ali Ghassemi ${ }^{1}$, Pedram Mohtashamzadeh $^{1}$, Setareh Taghikhani ${ }^{1}$, Khatereh Skokri ${ }^{3}$, Mohammad Yavari ${ }^{3}$, Seyed Ali Hosseini Zavareh ${ }^{2}$

Submission: July 06, 2021; Published: August 02, 2021

"Corresponding author: Young Researchers and Elite Club, Medical Department, Tehran Medical Sciences, Islamic Azad University, Tehran, Iran

\begin{abstract}
Patients with WPW syndrome are potentially at risk for ventricular arrhythmias due to conduction in the lateral passageway, resulting in very rapid ventricular depolarization if an atrial fibrillation or atrial fibrillation (AF) occurs. In patients with prognostic AF, electrophysiological studies of the heart and radiofrequency ablation (RF) may be treated. The cause of SCD in WPW syndrome is the rapid transfer of AF to the ventricles via AP, which causes ventricular fibrillation (VF). AF develops in one-fifth to one-third of patients with WPW syndrome; The reasons for this and the impact of AP on its development are not clear. Only a small percentage of patients with WPW syndrome (less than 1\%) are at risk for sudden cardiac death (SCD). The heart drug, digoxin, is contraindicated in adults with WPW syndrome. However, it is sometimes used to prevent the treatment of infants with WPW syndrome who do not have a ventricle before pregnancy. Some medications, such as verapamil, may increase the risk of ventricular fibrillation and should be used with caution.
\end{abstract}

Keywords: WPW syndrome; Ventricular fibrillation; Cardiac death; Electrocardiogram

Abbreviations: AVRT: Atrioventricular Reciprocating Tachycardia; ECG: Electrocardiogram; AV: Atrioventricular; WPW syndrome: WolfParkinson-White Syndrome; PSVT: Paroxysmal Supraventricular Tachycardia; AF: Atrial Fibrillation; VF: Ventricular Fibrillation; RFA: Radio Frequency Ablation; SPERRI: Shortest Pre-excited RR Interval; PR: Prothrombin Ratio; CHB: Complete Heart Block; SCI: Spinal Cord Injury; EWI: Electromechanical Wave Imaging; ERS: Early Repolarization Syndrome; ER: Early Repolarization; EPS: Electrophysiology Study; IVF: Idiopathic Ventricular Fibrillation; AVAP: Average Volume-Assured Pressure; SD: Sudden Death; SCD: Sudden Cardiac Death; EPT: Electroporation Therapy; PAF: Paroxysmal Atrial Fibrillation; AFL: Atrial Flutter; LTE: life-Threatening Event; PVI: Pulmonary Vein Isolation; PSQ: Patient Satisfaction Questionnaire

\section{Introduction}

Patients with WPW syndrome can be classified into two general categories: asymptomatic and symptomatic. The risk of cardiac arrest is mainly seen in the second category. Although this syndrome is most often identified by short PR and long QRS on the ECG ; But there is also evidence of a normal ECG that may have originated from a hidden or temporary lateral pathway. In these patients, two types of AVRT called orthodromic and antidro mic are also seen. The main difference between the two is in guiding the lateral path from the atrium to the ventricle or vice versa, in both cases, guiding in the opposite direction is the responsibility of $\mathrm{AV}$ [1].

Researchers and physicians over the years have found a strong association between the incidence of atrial fibrillation and ventricular fibrillation in people with WPW syndrome ; Of course, it is not possible to say for sure what are the main causes of AF in people with WPW; However, different theories that are seen in relation to the relationship between the two in different articles, indicate that genetic or environmental factors are effective in the simultaneous occurrence of the two [2].

According to experiments and clinical observations, the possibility of AF in people with overt WPW is higher than those with latent WPW [3].

In general, people with induced AF also have WPW syndrome; For treatment, they can greatly reduce or eliminate their induced AF problem with WPW treatment [4]. However, people with spontaneous AF cannot be treated with WPW; Because WPW is not the source of spontaneous AF creation. These people should try other ways to treat spontaneous AF [5]. 
Clinical studies show that even after successful APABLATION surgery, the possibility of AF relapse is still present, which in turn depends on independent and non-independent factors [4]. These factors include age and gender or even underlying problems such as genetic factors [3]. These cases also depend on the type and origin of AF and are very decisive [6].

Research has shown that sympathetic discharge can lead to malignant arrhythmias, and since the most common arrhythmias in patients with WPW syndrome are SVT, AF, VF; One of the most important points during anesthesia of these patients is to prevent the factors that can lead to malignant arrhythmias [7].

In a study that diagnosed a 39-year-old man with intermittent WPW and VF, inferior premature repolarization was observed in the absence of delta waves, which increases the likelihood of an arrhythmogenic substrate associated with premature repolarization in patients with overt WPW syndrome. Here we can attribute VF to inferior premature repolarization [8].

For the drug treatment of wpw syndrome, three drugs are commonly used: proxainamide, amiodarone and ibutilide. Proxinamide and ibutilide are mostly used for AF, but lowdose amiodarone has also been used to treat recurrent atrial arrhythmias Is [9].

Adenosine is another drug used with caution that under certain conditions (PSVT disorder) can aid in treatment and is even the first line of treatment in regular tachycardias in patients with stable symptoms [10]. It should also be noted that if WPW syndrome is associated with $\mathrm{AF}$, the use of most antiarrhythmic drugs, such as digoxin, is prohibited due to impaired conduction through the $\mathrm{AV}$ node and thus increased conduction through the sub-pathways [11]. According to a study conducted in a study, the success rate of subcutaneous pathway (AP) removal in RFA surgery has been reported to be more than $90 \%$, and the mortality rate in people with WPW syndrome and healthy people is not much different Slowly [6].

One of the most effective ways to significantly increase the success of ablation is to locate local electrical conduction pathways in the heart by EPS or electrophysiological studies of the heart [12]. While this method is very common and common, there are also risks to people being treated with this surgery; For example, in a study, a person who had this operation due to wpw syndrome had a problem with the mitral valve due to the catheter passing through it, and doctors had to perform an open-heart operation to fix it [13]. However, the success rate of this operation is still higher than drug treatment and patients are more likely to recover [14].

In the rare cases in which death from the syndrome has been reported, a person has suffered from an acute stroke with an acute mental illness in the past before the onset of acute symptoms of the syndrome [15]. One study found that in one-third of people with WPW syndrome, atrial fibrillation can be dangerous; But the most important cause of death in people with this syndrome is ventricular fibrillation [16]. A report in India found that people with the syndrome who exercised professionally or had a number of stressful occupations, such as piloting, were more likely to die [10].

3: As we all know, WPW syndrome is not inherited in most cases, but may be autosomal dominant with other congenital diseases (most commonly Ebstein) or part of the more complex May syndrome [17]. For example, two mutations in this syndrome are the G13513A mutation, which, like the common mutation in this syndrome (PRKAG2 mutation), causes a defect in the energy production process and as a result of this syndrome. Another is the A3243G mutation, with which WPW is one of the chances of having a history of disease in patients with melas syndrome $[18,19]$. The above mutation may actually be seen in patients who experience this syndrome at the same time as Lee syndrome, in which case the PSQ method is used to diagnose this mutation [20].

There have been changes in the way patients are diagnosed, the risk of more or less the disease, and their prioritization during clinical trials in recent years. For example, in the past it was thought that without The patient's symptoms and intermittent WPW are the two main factors for the lower risk of this syndrome. However, according to several studies, symptomatic patients are estimated to be at higher risk, but asymptomatic patients may also show a malignant arrhythmia as the first clinical manifestation [21].

\section{AF and WPW syndrome}

There is a higher risk of this disease in men, younger ages and there are several sub-pathways that it is better to use EPT to understand the inherent electrophysiological characteristics of $\mathrm{AP}$, regardless of the presence or absence of symptoms of atrial fibrillation [22].

In people with WPW, due to the presence of AP, the path and conduction path of electrical pulses are no longer limited to the AV pathway for transmission from the atrium to the ventricle. These electrical currents can circulate through the pathways created by the AP between the atrium and the ventricle; In such a way that it has considerable potential to cause supraventricular arrhythmias. One of the most important routes in these people is the AVRT route. These types of paths, which are of the AVRT type, are divided into two categories: ORTHODROMIC and ANTYDROMIC. In the first type, the electrical pulse enters the ventricle from the $\mathrm{AV}$ path and is ANTEGRADE and enters the atria through the AP as RETROGRADE. In the second case, electrical pulses enter the ventricle through the AP in the form of ANTEGRADE from the atrium to the ventricle and return to the atrium through the $\mathrm{AV}$ conductor path [RETROGRADE] [23,24].

AF in people with WPW depending on their origin into two types Is closed. Spontaneous and non-spontaneous. If the path of electric pulses in these people is ORTHODROMIC, the electrical stimuli are returned to the atrium. These returned pulses in the atrium may cause sporadic and irregular contractions and an 
area called inductive or non-spontaneous fibrillation. But if AF in individuals is independent of AP and WPW and these factors are not involved, then we say that fibrillation has a spontaneous origin [2]. It should be noted that the ORTHODROMIC pathway is much higher than other pathways in patients and practically a very small percentage of people less than $10 \%$ have an ANTYDROMIC pathway [25]. The presence of atrial fibrillation in people with WPW is considerably high, even up to about one-third. In affected individuals, AVRT can induce AF or even attack (PAF) by creating an ORTHODROMIC pathway, in which case it begins abruptly and ends abruptly. In infected people, there is a possibility of developing PSVT as AVNRT, which is very rare. AF or PAF in individuals may be dependent on the presence of AP (induction) or may be independent of AP (spontaneous) [2]. It is noteworthy that in a patient we can see both motion and antegrade in APs [26].

It is very difficult to distinguish whether the source of problems in people with AVRT or AVNRT, but one way to distinguish between the two is that in the AVNRT form, the wave after the QRS wave registers the ST part that is seen in the AVRT form. The face is DEPRESSION [27]. One of the most common mistakes in diagnosing AF in patients is that it is confused with ventricular tachycardia. In fact, it can be generally stated that atrial fibrillation with WPW is often not diagnosed correctly and should therefore be avoided. In the case of further training, these cases should be addressed [28].

As we know, AF is not very dangerous in healthy people, but in people with WPW it can cause complications, or even cause sudden death in people. One of the complications of atrial fibrillation, which occurs in people with WPW, can be considered a stroke, so that due to AF in the left atrium can be considered a clot that is one of the complications of atrial fibrillation. With the entry of this clot into the general circulation of the body and its transfer to the cerebral arteries, it is possible to observe clogging or blockage of cerebral blood vessels, which can cause irreversible complications for the person [29,30]. Another complication of $\mathrm{AF}$ in people with WPW is ventricular fibrillation (VF), which is caused by the emission of an electrical pulse through the AP from the atrium to the ventricle in the form of ANTEGRADE. Because AP, unlike the body's natural AV pathway, lacks the ability to limit current flow and pulse conduction, and can direct many pulses to the ventricle in much less time than the AV pathway, it can stimulate the ventricle to attack. And cause ventricular fibrillation, which if left untreated can lead to death. Although the risk of death and VF in general is very low, even in those who show a short EFFECTIVE REFRACTORY PERIOD on the ECG, it still exists, and emergency measures must be prepared [31]. Also, spontaneous (rather than inductive) VF is very, very rare in people with WPW, and VF is usually induced in individuals. In inductive VF, the role of $\mathrm{AP}$ and $\mathrm{AF}$ is very prominent [32].

In people with WPW who do not have AF, there is a low probability of activation of the above mechanisms in the event of an electric shock and may even lead to death [33].
There are factors that, if present, can cause Increased AF in people with WPW. One of the risk factors that may be involved in the development of AF is a mutation in the NEBL PITX2 genes that are present in people with WPW and can cause AF in these people [34]. Other factors include AP-dependent atrial vulnerability and the fact that MANIFEST Aps are more prone to $\mathrm{AF}$, and hypertension also provides the basis for spontaneous AF-independent AF [35]. With sex, it can be said that AF generally occurs more often in men than women $[26,36,38]$, in people with AVRT. The probability of induced AF is high, so AVRT itself is a very important risk factor for induced atrial fibrillation. Also, people with OVERT WPW are more likely to develop AF than those with INTERMITTENT WPW. People with multiple APs are also more likely to have AF, especially PAF. The location of the AP can also play a role in predicting AF. So that LEFT SIDE AP more than RIGHT AP and also RIGHT AP more than SEPTAL AP can predict the existence of AF in the future [26]. The presence of a large atrium in people, especially men, is another predictor of AF, and people with overt AP are more likely to develop AF [38]. Regarding the origin and risk factor of spontaneous $\mathrm{AF}$, we can also mention the association of sconduction delay activities around and around the pulmonary vain ostinum [39].

Treatment of people with WPW and AF requires great care. If the person is not in a stable state, the first thing that is suggested is cardioversion, which is always mentioned as an immediate and safe solution [40]. But if the person is in a stable state, drug therapy such as adenosine is used to treat SVT. Although maneuvers such as vagal maneuvers can also be used if the respondent is reentrant and or it was not enough to use drug therapy (adenosine IV). If adenosine was not responsive to SVT in these conditions, it could be said to be the cause of VF and VF-appropriate treatments should be performed [41]. ADENOSIN should also be used with caution as it may cause side effects and even lead to VF [3].

Also, the use of amiodarone in emergencies in people with WPW with AF is not recommended and CARDIOVERSION is recommended instead [40]. In pregnant women with WPW and $\mathrm{AF}$, there is a risk to the person as well as the fetus, which can still be used by CARDIOVERSION and is safe to use in pregnant women [42]. One of the treatments that is more aggressive but is also recommended for the treatment of WPW is APABLATION. By doing this, APs are eliminated, or their number is reduced, which in addition to treating WPW and removing the delta wave in the ECG by preventing AP from preventing induced AF. In those who do not have surgery, FLACAINID is used in combination with BISOPROLOL, which is an effective way to control PSVT or $\mathrm{AF}$, which can eventually eliminate the wave on the ECG [43]. However, AP Ablation can generally be used to treat people with overt or covert WPW, with or without AF [10].

People with WPW and AF still have AF after ablation, so there are different structures and mechanisms for the origin of $\mathrm{AF}$ that go beyond the direct connection between $\mathrm{AF}$ and $\mathrm{AP}$ and in (AVRTs are spontaneous AFs). But people who have had successful 
ablation surgery are much less likely to die than those who have not had ablation surgery, and their recurrent AF is much less likely to become VF [6].

Also in people who do PVI, which is a type of AP ablation, they may have PAF again, it seems that this can happen because the conduction pathways between the pulmonary vein and the left atrium are restored and [44] Also, mutations in genetic factors such as PITX2 and NEBL can cause recurrence of symptoms such as PAF, even if ablation is successful [35] , as well as risk factors for pre-existing AF and Postoperatively, they are also independent of each other, such as age, which can be a postoperative factor Age over 50 years after successful surgery have experienced a greater return of AF than other people [15]. Also, people with interatrial block may still have the possibility of AF returning after successful ablation surgery [4].

Studies have shown that the possibility of death in children due to WPW with AF, although low, is low. Also, in children with Ebstein syndrome, the possibility of developing LTE is greatly increased, and these events can even be [45]. Studies in children have also shown that LATENT AP, which is hidden in children with WPW, Rarely end in AVRT, but this is not zero and there is a risk of death in children due to VF [21].

\section{VF and WPW syndrome}

Sudden death in WPW can be the result of rapidly guided $\mathrm{AF}$ in the by-pass, which can lead to $\mathrm{VF}$, but this is potentially preventable. Although malignant arrhythmias according to EPS usually occur in symptomatic WPW individuals, the first sign in asymptomatic cases may be sudden death [45].

Because VF can lead to cardiac arrest, most WPW patients undergo RFA [46]. Lateral pathways are located, and because asymptomatic patients usually present with a good prognosis, RFA and EPT are required, and the electrophysiological characteristics of lateral pathways can identify individuals at risk of sudden death [21].

AF with pre-exited can also lead to VF, and WPW patients who have shown a course of VF must be electrophysiologically evaluated for risk classification and can be removed to remove the catheter bypass used ablation [47].

In an observation of pre-exited $\mathrm{AF}$, which can lead to $\mathrm{VF}$ and sudden death, we had a case in which AF persisted for 3 minutes, leading to VF and sudden cardiac death, but failed to recover due to attempts to defibrillate the patient [48].

Also, the diagnosis of AF with WPW is resistant to the operation of the electric demon version, is abnormal and can lead to death due to dysrhythmia [49].

Induction of VF in 2 of 109 children studied suggests that the prognosis of WPW in children may not be good, so all WPW patients, whether symptomatic or asymptomatic, should be evaluated for risk [50].
Both groups of symptomatic and asymptomatic children are at high risk for SD, and there is no difference between the two groups in atrial vulnerability that can lead to SCD [51].

In WPW, the delta wave is a sign of a bypass (AP), and APs are observed to be less common in children and adolescents aged 8-17 years than in adults [52].

In both symptomatic and asymptomatic groups, it was observed that in the group that did not perform RFA, in 1.5\% of patients, specifically in children, VF occurred, and in fact malignant arrhythmias and VF occurred in the group that There are no more cures [53].

Pregnancy in asymptomatic WPW patients predisposes to maternal arrhythmias, which can be life-threatening. When an arrhythmia occurs, high ventricular velocity depends on the characteristics of the bypass and VF can occur during high ventricular velocity. Give [54]. Of the 33 patients with PSVT, 3 had WPW for whom procaineamide was prescribed [55]. Prokinamide is the drug of choice for subclinical obstruction [55-57].

In patients with WPW who have pre-exited AF, the use of AV node blockers such as adenosine, digoxin, non-dihydropyridine, calcium channel Blockers, intravenous amiodarone) are contraindicated [43]. Because following their consumption, ventricular velocity becomes excessive (200-240 beats per minute) which can lead to catastrophic consequences such as $\mathrm{VF}$ and sudden death, and their prescription in these conditions is considered medical malpractice [56]. These AV node-blocking drugs reduce the number of impulses through the His-Purkingr system and increase conduction through the bypass, leading to increased ventricular velocity and the occurrence of VF during AF [57].

\section{Amiodarone: Contraindicated treatment}

in a number of patients who used amiodarone to prevent $\mathrm{VF}$ due to pre-exited AF converted AF to a normal sinus rhythm but in some cases caused hemodynamic instability with VF [3]. There is actually evidence that as long as amiodarone is converted to desethylamiodarone, it can act as a beta-receptor antagonist, blocking the AV node and converting AF to VF, so it cannot be AF as a first-line drug for every patient [58].

Patients with WPW are at risk for VF due to the rapid ventricular response due to AVAP and SD, but sometimes it is difficult to differentiate whether VF is related to WPW or not, so we can use tests to diagnose [59].

We can use tests such as drug stress testing or EPS, for example, to confirm whether VF is related to a known condition such as WPW. For example, if, after taking adenosine, there is no evidence of side effect, VF can be ruled out and IVF can be considered [60]. We know that adenosine is an atrioventricular node occlusion agent that facilitates the conduction of antigra via AP through a sinus rhythm, meaning that it can be used to expose 
delta waves in the ECG. Lateral impulses may be transmitted to the ventricle at high speed Which may lead to VF and sudden death [61].

WPW patients may be predisposed to VF due to their fastguided antidepressant bypass, and EPS and ablation of the upper leg bypass can prevent sudden death due to VF [58,61,62]. IVF is actually related to the normal heart. Or rather, IVF is a group of diseases whose first symptom is VF, but other known causes of VF include WPW [64]. Unintended VF is rare during catheter ablation or EPS, but special caution should be exercised during internal cardioversion, especially when injecting isoproterenol, as injecting increases ventricular vulnerability, which may be the main cause of VF in This step is [64].

In patients with WPW, the occurrence of transient MI due to coronary vasospasm can lead to VF, which can occur during RF ablation of the secondary pathway, close to this sub-pathway. Of course, this is rare, but its occurrence must be considered [65]. In patients with WPW, ventricular pre-stimulation leading to VF may be considered unrelated to $\mathrm{AF}$, and if it occurs alone and with other events such as MI due to coronary artery vasospasm or MI due to cocaine use and or does not coincide with $\mathrm{AF}$, in most cases cannot lead to death [32].

In fact, ventricular pre-stimulation means that instead of the ventricles being activated through the AV node and the Hess bundle, they are activated through the sub-pathway, which can lead to a worse condition, VF [66]. In fact, the same ventricular prestimulation can cause Flecainide can be used as an antiarrhythmic treatment for various arrhythmias [67]. ER can be seen in people with WPW, which can lead to IVF, but the effects of a sudden attack are not related to the presence or absence of ER, and if we experience a rapid ventricular response through the secondary pathway during sudden AF, VF can occur [68].

ER may be covered by delta waves and show up after ablation is removed, so if we see ER syndrome after removal of the subpathway, we should know that it can lead to VF, then sudden death due to VF in WPW occurs not only because of AF but also because of ERS [69]. Studies have shown that sildenafil is contraindicated in patients with acute coronary syndrome and arrhythmias that lead to death. During treatment, he underwent defibrillation [70].

\section{Nonpharmaceutical Interventions and surgeries}

There is generally a surgical procedure for the treatment of this disease and the removal of sub-pathways of message transmission, but there are two different methods, which are cryoablation: ablation using RF or Radio [71,72] Frequency. In general, the difference between these two ablation methods is in the mechanism of change in the heart tissue, which in the cryo method uses cold and RF through heat to remove these pathways. In a study, the two were compared, with the result that factors such as the sub-route model determine which method is more appropriate. But in general, due to the difference in the type of catheter, cryoablation is more suitable in areas where catheter stability is important due to having a more stable catheter [72].

In a study examining the failure rate of surgery with Cryo and $\mathrm{RF}$, it was reported that the use of $\mathrm{RF}$, despite the greater risk of heat than cryoablation and cold, can reduce the rate of return of the bypass as well as surgical failure [73].

That this disease did not show dangerous signs and symptoms, this operation is disputed between different studies and in some studies, this preventive operation has been suggested [53], and in others, there has been no emphasis on surgery and medication and observation and Observation of the disease by the treating physician until the danger arises is an alternative to surgery [66]. In one study, two infants diagnosed with wpw syndrome and the presence of lateral pathways on the right side of the heart were diagnosed using two injectable-oral infusions of flecainide and carvedilol. These two drugs are cited in the control of this disease [76]. Another study reported drug therapy in response to heart attacks by injecting flecainide esmolol Amiodarone into a 30-dayold infant who had previously used adenosine to control an arrhythmia that ultimately failed due to the patient's drug failure. Ablation required successful surgery [77].

One of the most important factors in the success of this surgery is marking and correctly addressing the side paths using ECG as well as EWI or Electromechanical wage imaging which Two- and three-dimensional images of the heart are taken, the location of the side paths can be marked. Using EWI methods due to the high quality of video evaluation, can help us find sub-routes better than ECG, but using two methods ECG and E WI at the same time, will certainly have the best results. However, limitations in the use of Ew, such as anatomical problems that make imaging difficult (such as anatomical problems in the braces) can be mentioned as disadvantages of using this method [71].

In a study of 92 patients, a total of 60 had AP on the left side of their heart, of which about 34 had AP in the LEFT FREE WALL area [73]. In a separate study, the two methods of retrograde transaortic stransseptal approach in left side AP ablutions were compared (the difference between the two is at the point of entry into the heart and ablation) Also, catheter transfer is easier than this route and also due to having a lower percentage of challenges (5.5\% for transaortic and $1.9 \%$ for trans septal) this method is known to be safer and which, of course, differ in different studies. it's obvious [78].

This surgery was successful in studies performed under two conditions:

WPW Symptomatic Syndrome and WPW Asymptomatic Syndrome. Asymptomatic surgery, in which the syndrome can only be detected by electrophysiological tests of high-risk groups, was as successful as the symptomatic condition. And to prevent the development of syndrome and cardiac arrhythmias or even the death of cardiac cells to a high extent [53]. 
Repeat this surgery if the study in several European countries failed, the result of the study was that 2 to $5 \%$ of ablutions performed for the first time were not successful and this operation to achieve recovery for patients, it is repeated. However, the repetition of this operation in some medical centers depends on the location of the bypasses, which may change the ablation method in the next time or not continue at all [79].

In another study, the success rate for these repetitive operations was reported to be $91 \%$. Considering the high success rate of this operation in the first stage, it can be inferred that finally, after one or two stages of ablation, the patient's recovery is very likely. However, we should not ignore the difficulties and challenges such as the position of APs that we encounter in different patients [80]. On the other hand, in another study among 3051 WPW patients who underwent ablation surgery, the recurrence rate of this disease after surgery was reported to be $4.9 \%$ [4].

to perform ablation for left aps of the heart, femoral artery and to perform Insert the ablations on the right side of the femoral vein of the catheter and after reaching the heart, according to the exact position of the catheter bypasses, and then start the ablation first with low energy and if there is no problem, we increase its power to 50 watts and thus perform ablation [81]. Although this is the best method, sometimes due to anatomical problems of venous, cardiac or arterial, this path may change and, for example, the problem of interruption in the inferior vena cava in a 24-yearold, forced the operator to insert a catheter from the superior vein It is a more complicated method for the catheter to enter and reach the ap site [82]. The time required for this surgery also varies from about 25 to 100 minutes, depending on the challenges and complexities we face in Harris [83].

Due to the catheter entering the heart through the arteries, care must always be taken not to damage the catheter in the path or even at the catheter destination due to the catheter colliding with existing cardiovascular structures. If possible, measures such as marking and Catheter observation for proper catheter movement and passage, observation of plasma markers such as troponin, after ablation, and to ensure the presence or absence of possible damage and even to prevent catheter passage, used vessels with a diameter of less than $5 \mathrm{~mm}$. The incidence of such errors is very low and, for example, in one study, the incidence of coronary artery damage during ablation was reported to be around $0.09 \%$ [84] ; However, with all the reported risk factors and even with the possibility of av block due to the sudden death of cardiac cells and other risks of this disease, cryo or RF surgery is required, [85] the use of marking systems With advanced 3D mapping to find the exact signs of side paths, it can greatly contribute to the success of the surgery [75]. Also, in patients with venous occlusion problems or anatomical problems or even pregnancy, performing this surgery can face challenges. It can be referred to the case report in which a 19-year-old pregnant woman, despite two problems of coronary sinus atresia and arteriovenous malformation, was successfully ablated by the lateral pathways in the left region of the heart [86]. However, a study referred to SCI or Silent Cerebral Infarct, which, as its name implies, is a problem in the blood supply to brain cells "after ablation" in a small number of people covered by this study ( 2 people or $10 \%$ of cases of ablation (However, the exact cause and extent of its association with ablation have not yet been determined) [83]. In addition to all of the above and the usefulness of this surgery, damage to blood vessels, especially coronary arteries, can be risky. Another to perform this surgery [87]. Another challenge we face is ablation at points close to the av node. In proportion to these challenges, we have changes in our methods. One of these successful methods is moving through the non-coronary cusp. Has a lower risk of damage to the av node. [88] Other problems during surgery include $\mathrm{CHB}$, or complete heart block, in a 16-year-old during transseptal puncture, resulting in damage to the av node, which can be caused by stretching of the septal wall. Atrial or catheter impact injury [89].

\section{Mortality rate and sudden death in WPW syndrome}

In reported sudden deaths due to WPW syndrome According to data from the ECG, people with PR distances of $250 \mathrm{~ms}$ are actually at risk of sudden death due to this syndrome. People with this PR interval are at the same risk of sudden death, regardless of whether they are an athlete or have little mobility [48].

One study noted that the majority of patients with the syndrome, who were male and white, had a heart rate of about $90 \%$ in those with symptoms, and a very small percentage, and about $7 \%$ syncope. With these data we conclude that a large percentage of sudden deaths onset of heart palpitations with symptoms, but a very small percentage of asymptomatic deaths were reported [90].

Atrial fibrillation is very common in WPW syndrome, in which atrial fibrillation causes atrial fibrillation, which is the most common cause of sudden death or arrhythmias [45]. In general, in a study of children, there was no significant association between exercise and sudden death from the syndrome, as many sudden deaths occurred during physical stability [91]. The syndrome is reported to be more dangerous in asymptomatic children than in adult athletes, causing a very small percentage of deaths, about one percent, in athletes. It can be said that the risk of this syndrome in competitive athletes (especially in the presence of underlying diseases such as hypertrophic cardiomyopathy) due to high stress, is higher than other groups so that in addition to noninvasive studies, invasive electrophysiological studies are needed to classify the risk. With criteria such as SPERRI is less than $250 \mathrm{~ms}$ [92].

Mortality is almost the same between people with the syndrome and healthy people, except those fewer deaths have been reported in older patients treated with catheter ablation [6]. In another cohort study, researchers found that most patients were asymptomatic during early AVRT, but may experience a recurrent arrhythmia every 5 years, but fewer had syncope or cardiac arrest be [22]. In children, atrial fibrillation is less commonly reported 
on the ECG but is not significantly different from adults. Because sudden death from atrial fibrillation has been reported, death and $\mathrm{AF}$ are directly related, which is more common at younger ages [93].

Another article on the sudden death of athletes states that sudden death in these individuals is complementary to high mobility and unexplained illness, and that WPW syndrome, as it may be unexplained, is one of the causes of death are these people [94]. As mentioned, the main cause of death in these people is atrial fibrillation, but a very important point is that this fibrillation increases the conduction velocity in the ventricles, so it can be said that atrial fibrillation causes ventricular fibrillation, which is the most important cause of sudden death. In these people [95].

An ECG report from a young woman who had syncope while climbing stairs found that asymptomatic people who smoked and drank alcohol were more likely to develop syncope due to the syndrome [96]. The paragraph above noted that AVRT is pronounced in sudden death. In fact, AVRT is an orthodromic tachycardia that begins more rapidly in WPW patients and causes atrial fibrillation to cause syncope or tachycardia in these individuals [97].

In the reported mortality from WPW syndrome, we can conclude that the most important concern in this syndrome is sudden death, but in children due to less specialized screening, we cannot get accurate statistics, but we can say that a small percentage of children due to abnormalities Died hearts suffered from this syndrome invisibly [98].

Another report found that Epstein and WPW abnormalities were more closely related, which is not very dangerous in pregnant mothers, with $16 \%$ of 153 pregnancies reported, but dangerous in people diagnosed with pregnancy. Because it can cause shortness of breath during pregnancy [99]. In a cohort study comparing the incidence of syncope and other factors associated with WPW syndrome in people under 59 years of age and people over 60 years of age, we reach the following results [100]:

(i) At older ages (more than 59) less syncope is reported $(12.5 \%)$.

(ii) The syndrome is less common in older people.

(iii) The disease is asymptomatic in younger people (less than 59 years of age) (35.5\%).

(iv) Atrial fibrillation is more common in the elderly (37.5\%).

(v) The elderly is more at risk (22\%).

A case report from a farmer reported a heart attack in which no underlying medical conditions, including diabetes, were reported during the medical examination, but the patient suffered from this syndrome, so it can be concluded that WPW syndrome and stroke can coexist with myocardial infarction, so immediate care is required for people who have the syndrome and experience chest pain. [101] Another case report noted that the WPW pattern, in ECG cannot become a syndrome during myocardial infarction, but this pattern alone can be fatal, which has been reported in chest pain [102].

In an article conducted in Tehran, out of 150 patients with this syndrome 20 people (1373\%) have experienced syncope As we know, syncope of this syndrome has no neurological origin and is caused by arthritis. May orthodontics is an atrial fibrillation and 16 of these 20 people have had this arrhythmia [103].

In a case involving a 45-year-old man suffering from schizophrenia, a person suddenly develops syncope. The man had no report of chest pain but was dizzy before syncope, so it can be concluded that atrial fibrillation is more important in these people than structural abnormalities that may appear suddenly and the person before may be asymptomatic [11].

WPW syndrome, along with Brugada syndrome, can be overlapping or related to each other, which is very rare. But in WPW syndrome, AVRT may turn into atrial fibrillation, which causes atrial fibrillation (PAF) paroxysm in these people.

\section{References}

1. Chhabra L, Goyal A, Benham MD (2020) Wolff Parkinson white syndrome (WPW). StatPearls.

2. Centurión OA, Shimizu A, Isomoto S, Konoe A (2008) Mechanisms for the genesis of paroxysmal atrial fibrillation in the Wolff-Parkinson-White syndrome: intrinsic atrial muscle vulnerability vs. electrophysiological properties of the accessory pathway. Europace 10(3): 294-302.

3. Acharya D, Rane S, Bohora S, Kevadiya H (2020) Incidence, clinical, electrophysiological characteristics and outcomes of patients with Wolff-Parkinson-White Syndrome and atrial fibrillation. Indian Pacing and Electrophysiology Journal 20(1): 3-7.

4. Wu JT, Zhao DQ Li FF, Zhang LM, Hu J, et al. (2020) Effect of pulmonary vein isolation on atrial fibrillation recurrence after accessory pathway ablation in patients with Wolff-Parkinson-White syndrome. Clinical Cardiology 43(12): 1511-6.

5. Kawabata M, Goya M, Takagi T, Yamashita S, Iwai S, et al. (2016) The impact of B-type natriuretic peptide levels on the suppression of accompanying atrial fibrillation in Wolff-Parkinson-White syndrome patients after accessory pathway ablation. Journal of Cardiology 68(6): 485-491.

6. Bunch TJ, May HT, Bair TL, Anderson JL, Crandall BG, et al. (2015) Long-term natural history of adult Wolff-Parkinson-White syndrome patients treated with and without catheter ablation. Circulation: Arrhythmia and Electrophysiology 8(6): 1465-1471.

7. SABUNCU Ü, YAĞAR S, YÖMEN VY (2018) Normalization of Electrocardiography Pattern Due to Anesthesia in a Patient with WolffParkinson-White Syndrome During Non-Cardiac Surgery. Turkiye Klinikleri Cardiovascular Sciences 30(2): 82-5.

8. Takahashi N, Shinohara T, Hara M, Saikawa T (2012) Wolff-ParkinsonWhite syndrome concomitant with idiopathic ventricular fibrillation associated with inferior early repolarization. Internal Medicine 51(14): 1861-1864.

9. Fengler BT, Brady WJ, Plautz CU (2007) Atrial fibrillation in the WolffParkinson-White syndrome: ECG.recognition and treatment in the ED. The American journal of emergency medicine 25(5): 576-583. 


\section{Novel Approaches in Drug Designing \& Development}

10. Sethi KK, Dhall A, Chadha DS, Garg S, Malani SK, et al. (2007) WPW and preexcitation syndromes. Journal-Association of Physicians of India 55(R): 10 .

11. Thanavaro JL, Thanavaro S (2010) Clinical presentation and treatment of atrial fibrillation in Wolff-Parkinson-White syndrome. Heart \& Lung 39(2): 131-136.

12. Ardakani MB, Dehghani F, Sarebanhassanabadi M, Yalameh A, Behjat M, et al. (2020) Impact of accessory pathway location on electrophysiologic characteristics and ablation success. Critical pathways in cardiology 19(2): 94-97.

13. Penaranda Canal JG, Enriquez-Sarano M, Asirvatham SJ, Munger TM, Friedman PA, et al. (2013) Mitral valve injury after radiofrequency ablation for Wolff-Parkinson-White syndrome. Circulation 127(25): 2551-2552.

14. Pietrzak R, Franke M, Gawałko M, Lodziński P, Balsam P, et al. (2020) Success rate and safety of catheter ablation in preexcitation syndrome: A comparison between adult and pediatric patients. Cardiology journal.

15. Borregaard R, Lukac P, Gerdes C, Møller D, Mortensen PT, et al. (2015) Radiofrequency ablation of accessory pathways in patients with the Wolff-Parkinson-White syndrome: the long-term mortality and risk of atrial fibrillation. Ep Europace17(1): 117-122.

16. Qiu M, Lv B, Lin W, Ma J, Dong H (2018) Sudden cardiac death due to the Wolff-Parkinson-White syndrome: A case report with genetic analysis. Medicine 97(51): e13248

17. Ehtisham J, Watkins H (2005) Is Wolff-Parkinson-White syndrome a genetic disease?. Journal of cardiovascular electrophysiology 16(11) 1258-1262.

18. Wang SB, Weng WC, Lee NC, Hwu WL, Fan PC, et al. (2008) Mutation of mitochondrial DNA G13513A presenting with Leigh syndrome, Wolff-Parkinson-White syndrome and cardiomyopathy. Pediatrics \& Neonatology 49(4): 145-149.

19. Sproule DM, Kaufmann P, Engelstad K, Starc TJ, Hordof AJ, et al. (2007) Wolff-Parkinson-White syndrome in patients with MELAS. Archives of neurology 64(11): 1625-1627.

20. Ruiter EM, Siers MH, van den Elzen C, van Engelen BG, Smeitink JA, et al. (2007) The mitochondrial 13513G> A mutation is most frequent in Leigh syndrome combined with reduced complex I activity, optic atrophy and/or Wolff-Parkinson-White. European Journal of Human Genetics 15(2): 155-161.

21. Pappone C, Vicedomini G, Manguso F, Baldi M, Petretta A, et al. (2015) The natural history of WPW syndrome. European Heart Journal Supplements 17(suppl_A): A8-11.

22. Pappone C, Vicedomini G, Manguso F, Baldi M, Pappone A, et al. (2012) Risk of malignant arrhythmias in initially symptomatic patients with Wolff-Parkinson-White syndrome: results of a prospective long-term electrophysiological follow-up study. Circulation 125(5): 661-668.

23. Yugo D, Yuniadi Y (2014) Atrial Fibrillation in WPW Syndrome Indonesian Journal of Cardiology 35(2): 87-95.

24. Kwon BS, Bae EJ, Kim GB, Noh CI, Choi JY, et al. (2010) Septal dyskinesia and global left ventricular dysfunction in pediatric WolffParkinson-White syndrome with septal accessory pathway. Journal of cardiovascular electrophysiology 21(3): 290-295.

25. Brembilla-Perrot B, Pauriah M, Sellal JM, Zinzius PY, Schwartz J, et al. (2013) Incidence and prognostic significance of spontaneous and inducible antidromic tachycardia. Europace 15(6): 871-876.

26. Szumowski Ł, Orczykowski M, Derejko P, Szufladowicz E, Urbanek P, et al. (2009) Predictors of the atrial fibrillation occurrence in patients with Wolff-Parkinson-White syndrome. Kardiologia Polska (Polish Heart Journal) 67(9): 973-978.

27. Chee YC, Ang JG (2018) A case of supraventricular tachycardia associated with Wolff-Parkinson-White syndrome. Journal of Medical Cases 9(2): 54-57.

28. Koźluk E, Timler D, Zyśko D, Piątkowska A, Grzebieniak T, et al. (2015) Members of the emergency medical team may have difficulty diagnosing rapid atrial fibrillation in Wolff-Parkinson-White syndrome. Cardiology journal 22(3): 247-252.

29. Blomstrom Lundqvist C, Lip GY, Kirchhof P (2011) What are the costs of atrial fibrillation?. Europace 13(suppl_2): ii9-12.

30. Brembilla-Perrot B, Delobelle J, Zinzius PY, Jarmouni S, Martins RP, et al. (2011) 180 Is it a risk of stroke in Wolff Parkinson White syndrome?. Archives of Cardiovascular Diseases Supplements 3(1): 58-59.

31. Obeyesekere M, Gula LJ, Skanes AC, Leong-Sit P, Klein GJ (2012) Risk of sudden death in Wolff-Parkinson-White syndrome: how high is the risk?. Circulation 125: 659-660.

32. Aranyo J, Bazan V, Rueda F, Sarrias A, Bisbal F, Villuendas R (2019) Ventricular fibrillation in a patient with Wolff-Parkinson-White syndrome unrelated to pre-excited atrial fibrillation. Annals of Noninvasive Electrocardiology 24(6): e12662.

33. Hafeez I, Sohail MM, Lone A, Gupta A, Iqbal K, et al. (2013) Low Voltage Electric Injury induced Atrial Fibrillation as a Presenting Feature of Wolff-Parkinson-White Syndrome: A Case Report. Oman medical journal 28(6): e061.

34. Coban-Akdemir ZH, Charng WL, Azamian M, Paine IS, Punetha J, et al. (2020) Wolff-Parkinson-White syndrome: De novo variants and evidence for mutational burden in genes associated with atrial fibrillation. American Journal of Medical Genetics Part A 182(6): 13871399.

35. Chen M, Feng X, Sun J, Wang Q Zhang P, et al. (2015) Risk factors responsible for atrial fibrillation development between symptomatic patients with concealed or manifest atrioventricular accessory pathways. IJC Heart \& Vasculature 7: 69-75.

36. Duszańska A, Lenarczyk R, Kowalski O, Streb W, Kukulski T, et al. (2007) The influence of atrioventricular and atrioventricular nodal reentrant tachycardia on left ventricular systolic and diastolic function. Cardiology journal 14(2): 160-166

37. Schwieler JH, Zlochiver S, Pandit SV, Berenfeld O, Jalife J, et al. (2008) Reentry in an accessory AV pathway as a trigger for AF initiation in manifest WPW syndrome: a matter of reflection?. Heart rhythm: the official journal of the Heart Rhythm Society 5(9): 1238-1247.

38. Hertervig E, Kongstad O, Ljungstrom E, Olsson B, Yuan S (2008) Pulmonary vein potentials in patients with and without atrial fibrillation. Europace 10(6): 692-697.

39. Tijunelis MA, Herbert ME (2005) Myth: Intravenous amiodarone is safe in patients with atrial fibrillation and Wolff-ParkinsonWhite syndrome in the emergency department. Canadian Journal of Emergency Medicine 7(4): 262-265.

40. Kotadia ID, Williams SE, O Neill M (2020) Supraventricular tachycardia: An overview of diagnosis and management. Clinical Medicine 20(1): 43.

41. Tak T, Berkseth L, Malzer R (2012) A case of supraventricular tachycardia associated with Wolff-Parkinson-White syndrome and pregnancy. WMJ111(5): 228-232.

42. Jae-Jin K, Doh JH, Lee SY (2019) Effects of Bisoprolol and Flecainide in an Elderly Patient with Paroxysmal Supraventricular Tachycardia and Atrial Fibrillation in Wolff-Parkinson-White Syndrome. Int J Clin Cardiol 6: 138.

43. Iqbal M, Jena A, Park HS, Baek YS, Lee KN, et al. (2017) Value of adenosine test to reveal dormant conduction or adenosine-induced atrial fibrillation after pulmonary vein isolation. Journal of arrhythmia 33(6): 602-607. 


\section{Novel Approaches in Drug Designing \& Development}

44. Etheridge SP, Escudero CA, Blaufox AD, Law IH, Dechert-Crooks BE, et al. (2018) Life-threatening event risk in children with Wolff-ParkinsonWhite syndrome: a multicenter international study. JACC: Clinical Electrophysiology 4(4): 433-444

45. Stokke MK, Edvardsen TE, Astrom Aneq M, Jensen HK, Bundgaard $\mathrm{H}$, et al. (2018) P769 Electrical changes do not precede changes in cardiac morphology or function in a substantial subset of patients with arrhythmogenic cardiomyopathy. EP Europace 20(Suppl_1): i133.

46. Yamada T, Jennings JM, McElderry HT, Doppalapudi H, Epstein AE, et al. (2009) Catheter ablation of a posteroseptal accessory pathway in a case with congenital long QT syndrome. International heart journal 50(2): 259-262.

47. Olen MM, Baysa SJ, Rossi A, Kanter RJ, Fishberger SB (2016) WolffParkinson-White syndrome: a stepwise deterioration to sudden death. Circulation 133(1): 105-106

48. Miraglia D, Marini O (2019) Profound Hypotension in Supraventricular Tachycardia with Intermittent Wolff-Parkinson-White Syndrome Refractory to Cardioversion. American Journal of Medical Case Reports 7(9): 210-213.

49. Ylldırım I, Özer S, Karagöz T, Şahin M, Özkutlu S, et al. (2015) Clinical and electrophysiological evaluation of pediatric Wolff-ParkinsonWhite patients. Anatolian journal of cardiology15(6): 485-490.

50. Di Mambro C, Russo MS, Righi D, Placidi S, Palmieri R, et al. (2015) Ventricular pre-excitation: symptomatic and asymptomatic children have the same potential risk of sudden cardiac death. Ep Europace17(4): 617-621.

51. Dhungana M, Rajbhandari S, Shaha KB, Sharma M, et al. (2013) The Clinical and Electrophysiological Features in Patients with WolffParkinson-White Syndrome. Nepalese Heart Journal 10(1): 17-19.

52. Pappone C, Vicedomini G, Manguso F, Saviano M, Baldi M, et al. (2014) Wolff-Parkinson-White syndrome in the era of catheter ablation: insights from a registry study of 2169 patients. Circulation 130(10): 811-819.

53. Erden İA, Ayhan B, Canbay Ö, Aypar Ü, Aycan İÖ (2013) Cesarean Section In a Patient With Wolff-Parkinson-White Syndrome Under Spinal Anesthesia. Düzce Tıp Fakültesi Dergisi 15(1): 66-67.

54. Li JM, Nguyen C, Joglar JA, Hamdan MH, Page RL (2008) Frequency and outcome of arrhythmias complicating admission during pregnancy: Experience from a high-volume and ethnically-diverse obstetric service. Clinical Cardiology: An International Indexed and PeerReviewed Journal for Advances in the Treatment of Cardiovascular Disease 31(11): 538-541.

55. Hashemi B, Pishgahi M, Maleki M (2014) Worsened Dysrhythmia after Chemical Cardioversion with Digoxin; a Case of Malpractice. Emergency 2(3): 147-149.

56. Kobayashi K, Ikeda T (2012) Irregular wide QRS complex tachycardia without structural heart disease. Journal of Arrhythmia 28(5): 307309

57. Leiria TL, Mantovani A, de March Ronsoni R, Pires LM, Kruse ML, et al. (2012) Ventricular fibrillation during amiodarone infusion in a patient with Wolff-Parkinson-White syndrome and atrial fibrillation: a case report. Journal of Medical Cases 3(5): 300-303.

58. Oshima T, Fujiu K, Matsuda J, Matsubara T, Hasumi E (2019) Pulseless Electric Activity with Pre-Excitation Idiopathic Ventricular Fibrillation and Fasciculoventricular Accessory Pathway. International heart journal 18-546.

59. Miyoshi M, Kondo H, Shinohara T, Yufu K, Nakagawa M, et al. (2019) Idiopathic Ventricular Fibrillation Manifesting Delta-wave during Hypothermia Treatment. Internal Medicine 58(3): 401-404.

60. Gungor B, Alper AT (2013) Malignant arrhythmia as the first manifestation of Wolff-Parkinson-White syndrome: a case with minimal preexcitation on electrocardiography. West Indian Med J 62(7): 672-624

61. Jaiswal A, Heretis K, Goldbarg S (2013) Coexistent Brugada syndrome and Wolff-Parkinson-White syndrome: what is the optimal management? Indian pacing and electrophysiology journal 13(5): 173177.

62. Champagne J, Geelen P, Philippon F, Brugada P (2005) Recurrent cardiac events in patients with idiopathic ventricular fibrillation, excluding patients with the Brugada syndrome. BMC medicine 3(1): 1-6.

63. Park YM, Lee HS, Lim RS, Choi JI, Lim HE, et al. (2013) Inadvertently developed ventricular fibrillation during Electrophysiologic study and catheter ablation: incidence, cause, and prognosis. Korean circulation journal 43(7): 474.

64. Hosaka Y, Chinushi M, Takahashi K, Ozaki K, Yanagawa T, et al. (2009) Coronary vasospasm triggered ventricular fibrillation delayed after radiofrequency ablation of the right accessory pathway. Europace 11(11): 1554-1556.

65. Beatson K, Khorsandi M, Grubb N (2013) Wolff-Parkinson-White Syndrome and myocardial infarction in ventricular fibrillation arrest: a case of two one-eyed tigers. QJM: An International Journal of Medicine 106(8): 755-757.

66. Chen F, Richard S, D Andrea G, Grandjean C, Eap Chin B (2016) WolffParkinson-White syndrome in an adolescent with depression. Swiss Archives of Neurology Psychiatry and Psychotherapy 167(3): 94-96.

67. Mizumaki K, Nishida K, Iwamoto J, Nakatani Y, Yamaguchi Y, et al. (2011) Early repolarization in Wolff- Parkinson- White syndrome: prevalence and clinical significance. Europace 13(8): 1195-1200.

68. Nauchi M, Sakai T, Sugisaki Y, Ito Y (2019) Revelation of early repolarization by eliminating accessory pathway in manifest WolffParkinson-White syndrome: A case report. Journal of arrhythmia 35(2): 300-302.

69. Inci S, Izgu I, Aktas H, Dogan P, Dogan A (2015) Ventricular fibrillation development following atrial fibrillation after the ingestion of sildenaphil in a patient with Wolff-Parkinson-White syndrome. Intractable \& rare diseases research 4(3): 159-161.

70. Melki L, Grubb CS, Weber R, Nauleau P, Garan H, et al. (2019) Localization of accessory pathways in pediatric patients with WolffParkinson-White syndrome using 3D-rendered electromechanical wave imaging. JACC: Clinical Electrophysiology 5(4): 427-437.

71. Tuzcu V, Gonzalez MB, Schranz D (2006) Cryoablation: better catheter stability compared to RF ablation. Anadolu Kardiyol Derg 6(2): 182184.

72. Yontar OC (2021) Evaluation of Efficacy and Safety of Various Catheter Ablation Mtehods in WolffParkinson-White Syndrome. Sabuncuoglu Serefeddin Health Sciences 3(1): 13-21.

73. Pappone C, Manguso F, Santinelli R, Vicedomini G, Sala S, et al (2014) Radiofrequency ablation in children with asymptomatic Wolff- Parkinson-White syndrome. New England journal of medicine 351(12): 1197-1205.

74. Kulig J, Koplan BA (2010) Wolff-Parkinson-White syndrome and accessory pathways. Circulation 122(15): e480-e483.

75. Sekine M, Masutani S, Imamura T, Iwamoto Y, Muraji S, et al. (2019) Improvement in dyssynchrony with pharmacological ablation of right-sided accessory pathwayinduced cardiomyopathy in infants. International heart journal 60(5): 1201-1205

76. Ergül Y, Öztürk E, Özgür S (2019) Successful radiofrequency ablation of accessory pathway associated with left atrial appendage aneurysm in a low birthweight premature patient. Turkish Journal of Pediatrics 61(1): 61(1). 
77. Alkahachi HR, Kadhum MA, Khalaf KS (2020) A Comparison Study between the Trans-Septal and the Trans-Aortic Approaches in Left Sided Accessory Pathway Ablation in Ibn Albitar Cardiac Center. Iraqi Postgraduate Medical Journal 19(2).

78. Svendsen JH, Dagres N, Dobreanu D, Bongiorni MG, Marinskis G, et al. (2013) Current strategy for treatment of patients with WolffParkinson-White syndrome and asymptomatic preexcitation in Europe: European Heart Rhythm Association survey. Europace 15(5): 750-753

79. Sacher F, Wright M, Tedrow UB, O Neill MD, Jais P, et al. (2010) WolffParkinson-White ablation after a prior failure: a 7year multicentre experience. Europace 12(6): 835-841.

80. Ozenc S, Iscen S, Kibrisli E, Tok D, Parlak A, et al. (2014) Prophylactic accessory-pathway ablation in asymptomatic patients with a WolffParkinson-White electrocardiographic pattern. European review for medical and pharmacological sciences 18(7): 981-984.

81. Bala P, Ali MA, Reza AQ, Khan MH, Bala K. Challenging Approach to Rare Case: Radiofrequency Catheter Ablation of WPW Syndrome in a Patient with Interruption of the Inferior Vena Cava.

82. Głowniak A, Janczarek M, Tarkowski A, Wysocka A, SzczerboTrojanowska M, et al. (2019) Silent Cerebral Infarcts Following Left-Sided Accessory Pathway Ablation in Wolff-Parkinson White (WPW) Syndrome: A Preliminary Report. Medical science monitor: international medical journal of experimental and clinical research 25 : 1336.

83. Zheng MF, Wang Z, Bao ZY (2020) Myocardial injury and pericarditis after combined left atrial and coronary sinus ablation in WolffParkinson-White syndrome: a case report. BMC cardiovascular disorders 20(1): 1-5.

84. Silva G, de Morais GP, Primo J, Sousa O, Pereira E, et al. (2013) Aborted sudden cardiac death as first presentation of Wolff-Parkinson-White syndrome. Revista Portuguesa de Cardiologia 32(4): 325-329.

85. Patel SM, McLeod CJ, Friedman PA, Liu XK, Asirvatham SJ (2011) Successful ablation of a left-sided accessory pathway in a patient with coronary sinus atresia and arteriovenous fistula: clinical and developmental insights. Indian pacing and electrophysiology journa 11(2): 43-49.

86. Wongcharoen W, Lin YJ, Chung FP, Chen YY, Chao TF, et al. (2018) Radiofrequency ablation of accessory pathways in patients with the Wolff-Parkinson-White syndrome: long-term risk of mortality and coronary events. Ep Europace 20(6): 1035-1042.

87. Gafforov SU, Yakubov AA (2019) A case of successful ablation of accessory right anterior-septal pathway (parahisian) through the non-coronary cusp: case report. Международный журнал сердца и сосудистых заболеваний 7(24 (eng))

88. .Schweis F, Ho G, Krummen DE, Hoffmayer K, Birgersdotter-Green U, et al. (2019) Transient complete heart block following catheter ablation of a left lateral accessory pathway. Journal of arrhythmia 35(1): 155157.

89. Finocchiaro G, Papadakis M, Behr ER, Sharma S, Sheppard M (2017) Sudden cardiac death in pre-excitation and Wolff-Parkinson-White: demographic and clinical features. Journal of the American College of Cardiology 69(12): 1644-1645.
90. Peinado R, Merino JL, Gnoatto M, Arias MA (2005) Atrial fibrillation triggered by postinfarction ventricular premature beats in a patient with Wolff-Parkinson-White syndrome. EP Europace 7(3): 221-224.

91. Rao AL, Salerno JC, Asif IM, Drezner JA (2014) Evaluation and management of Wolff-Parkinson-White in athletes. Sports health 6(4): 326-332.

92. Jung HJ, Ju HY, Hyun MC, Lee SB, Kim YH (2011) Wolff-ParkinsonWhite syndrome in young people, from childhood to young adulthood: relationships between age and clinical and electrophysiological findings. Korean journal of pediatrics 54(12): 507-511.

93. Germann CA, Perron AD (2005) Sudden cardiac death in athletes: a guide for emergency physicians. The American journal of emergency medicine 23(4): 504-509.

94. Klein GJ, Gula LJ, Krahn AD, Skanes AC, Yee R (2009) WPW pattern in the asymptomatic individual: has anything changed?. Circulation: Arrhythmia and Electrophysiology 2(2): 97-99.

95. Chang ST, Chern MS (2005) Sudden death in Wolff-Parkinson-White syndrome combined with syncope: a case report. International Journal of Clinical Practice 147: 15-18.

96. West JJ, Mounsey JP (2008) Wolff-Parkinson-White Syndrome and Asymptomatic Ventricular Pre-Excitation: Implications in Sports Cardiology. Current sports medicine reports 7(2): 93-99.

97. Chubb H, Ceresnak SR (2020) A proposed approach to the asymptomatic pediatric patient with Wolff-Parkinson-White pattern. HeartRhythm case reports $6(1): 2-7$.

98. Katsuragi S, Kamiya C, Yamanaka K, Neki R, Miyoshi T, et al. (2013) Risk factors for maternal and fetal outcome in pregnancy complicated by Ebstein anomaly. American journal of obstetrics and gynecology 209(5): 452-e1-e6.

99. Brembilla Perrot B, N da OY, Huttin O, Chometon F, et al. (2008) Wolff-Parkinson-White syndrome in the elderly: clinical and electrophysiological findings. Archives of cardiovascular diseases 101(1): 18-22.

100. Tang XG, Wen J, Zhang XS, Li XJ, Jiang DC (2018) Acute myocardial infarction in a patient with Wolff-Parkinson-White syndrome. Journal of Geriatric Cardiology 15(9): 605-608.

101. Iqbal AM, Ghazni MS, Mubarik A, Zubair N, Jamal SF (2019) The Conversion of Wolff-Parkinson-White (WPW) Pattern into WPW Syndrome in the Presence of Ischemia: A Case Report. Cureus11(2): e4147.

102. Aslani A, Kazemiasl S, Moradi M, Kafi M, Kheyrkhah J (2010) Frequency of syncope in patients with accessory atrioventricular connection. International Cardiovascular Research Journal 4 (1): e67667.

103. Shi S, Liu T, Barajas-Martinez H, Pfeiffer R, Jiang H, et al. (2017) Atrial fibrillation associated with Wolff-Parkinson-White syndrome in a patient with concomitant Brugada syndrome. HeartRhythm case reports $3(1): 13-17$. 


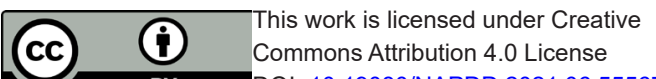

mons Attribution 4.0 License

DOI: 10.19080/NAPDD.2021.06.555679
Your next submission with Juniper Publishers will reach you the below assets

- Quality Editorial service

- Swift Peer Review

- Reprints availability

- E-prints Service

- Manuscript Podcast for convenient understanding

- Global attai nment for your research

- Manuscript accessibility in different formats

( Pdf, E-pub, Full Text, Audio)

- Unceasing customer service

Track the below URL for one-step submission https://juniperpublishers.com/online-submission.php 